\title{
Novel Crystallization Behaviors of Zr-Based Metallic Glass Under Thermo-Mechanical Coupled Fatigue Loading Condition
}

\author{
Zhi-Chao Ma ${ }^{1,2} \cdot$ Xiao-Xi Ma $^{1} \cdot$ Hong-Wei Zhao ${ }^{1} \cdot$ Fu Zhang ${ }^{1} \cdot$ Li-Ming Zhou $^{1} \cdot$ Lu-Quan Ren $^{2}$
}

Received: 27 September 2018 / Revised: 4 December 2018 / Published online: 27 February 2019

(C) The Chinese Society for Metals (CSM) and Springer-Verlag GmbH Germany, part of Springer Nature 2019

\begin{abstract}
Novel crystallization behaviors of $\mathrm{Zr}_{55} \mathrm{Cu}_{30} \mathrm{Al}_{10} \mathrm{Ni}_{5}$ bulk metallic glass are investigated. On the one hand, mixed oxides, including $\mathrm{CuO}, \mathrm{CuAlO}_{2}, \mathrm{CuAl}_{2} \mathrm{O}_{4}$ and $\mathrm{ZrO}_{2}$, show sequential oxidation process determined by coupling effects of specific cyclic load and temperature. On the other hand, at a temperature $\left(100^{\circ} \mathrm{C}\right)$ by far lower than $T_{g}$ of $412{ }^{\circ} \mathrm{C}$, under cyclic loading condition, non-oxidized binary alloy $\mathrm{CuZr}_{2}$ is precipitated; the thermo-mechanical coupled effects of temperature below $T_{g}$ and fatigue accumulation on the non-oxidized crystallization behaviors are revealed. Meanwhile, at a constant temperature of $400{ }^{\circ} \mathrm{C}$, by comparing among the XRD patterns, respectively, obtained from tensile, creep and fatigue fractures, the dominating effect of cyclic load on the generation of non-oxidized $\mathrm{CuZr}_{2}$ is verified. Furthermore, the crystallization behavior of amorphous phases under cyclic loading condition is observed through TEM micrograph and diffraction pattern at $100{ }^{\circ} \mathrm{C}$.
\end{abstract}

Keywords Bulk metallic glass $\cdot$ Fatigue $\cdot$ Thermo-mechanical coupling $\cdot$ Crystallization

\section{Introduction}

Due to the structural properties of short-range order and long-range disorder, such as a pressure-induced long-range topological ordered structure in metallic glasses revealed by Zeng et al. [1] and nominally "disordered" short-range order of the nearest-neighbor atoms observed by Sheng et al. [2] , bulk metallic glasses (BMGs) [3-5] exhibit excellent mechanical properties and thermostability. Compared with crystal alloys, BMGs exhibit more excellent performances, including favorable strength, hardness, toughness, corrosion resistance, wear resistance, due to the nonexistent crystal defect and lattice defect [6-8]. The static mechanical properties of metallic glasses, including tensile, bending, compressive, magnetoelastic coupled mechanism [9] and thermo-mechanical coupled properties [10-12], have been extensively studied. For example, Clinton et al. [13] revealed

Available online at http://link.springer.com/journal/40195

Li-Ming Zhou

lmzhou@jlu.edu.cn

1 School of Mechanical and Aerospace Engineering, Jilin University, Changchun 130025, China

2 Key Laboratory of Bionic Engineering Ministry of Education, Jilin University, Changchun 130025, China the enhanced tensile ductility and reduced strength of a $\mathrm{Zr}$ based BMG matrix alloy, and Ketov et al. [14] investigated the effects of thermo-stress on static constitutive relations of $\mathrm{Zr}_{62} \mathrm{Cu}_{24} \mathrm{Fe}_{5} \mathrm{Al}_{9} \mathrm{BMG}$ and $\mathrm{Zr}_{46} \mathrm{Cu}_{46} \mathrm{~A}_{17} \mathrm{Gd}_{1}$ BMG. Considering the structural failures are frequently attributed to the cyclic load or thermo-mechanical fatigue $[3,15]$, the property evolutions and failure mechanisms of Zr-based BMGs under service condition, involving high temperature and cyclic load, need to be taken into account.

Meanwhile, due to relatively low glass transition temperatures $T_{g}$, Zr-based BMGs exhibit relatively low critical crystallization temperature. The crystallization processes in amorphous phases are sensitive to temperature [16], and the liquid-like atomic alignments [17] are gradually ordered as the temperature increases [18]. Actually, by using a transmission electron microscope (TEM) integrated with a controllable heating stage, the crystallization of BMGs could be directly observed from the micrograph and diffraction pattern [19]. Crystallization behaviors of Zr-based BMGs induced by the coupling effects of temperature [20] and mechanical stress would result in rapid weakening of thermo-mechanical resistance and degradation of static and dynamic mechanical properties. For instance, Kim et al. [21] revealed that the local contact deformation under quasistatic nanoindentation results in $\mathrm{Zr}_{2} \mathrm{Ni}$ nanocrystallization of a $\mathrm{Zr}-\mathrm{Cu}-\mathrm{Ni}-\mathrm{Al}-\mathrm{Ti}$ BMG at room temperature. Kai et al. 
[22] studied the crystallization and oxidation behavior of $\mathrm{Zr}-\mathrm{Cu}-\mathrm{Al}-\mathrm{Ni} \mathrm{BMG}$ at $300-425^{\circ} \mathrm{C}$, and a significant change in the fatigue properties at high temperature was discussed. Furthermore, at a temperature below $T_{g}$, alternating stress with high frequency would also promote the crystallization process [10, 12, 23]. Kato et al. [23] revealed the partial ultrasound-accelerated crystallization mechanism, which is mainly caused by accumulation of atomic jumps. Therefore, considering the potential existing coupling effects of temperature and fatigue accumulation on crystallization, further understanding of crystallization behaviors of Zr-based BMG would extend their applications under thermo-mechanical fatigue conditions. This paper focuses on the novel crystallization behaviors of $\mathrm{Zr}_{55} \mathrm{Cu}_{30} \mathrm{Al}_{10} \mathrm{Ni}_{5}$ BMG by means of a novel thermo-mechanical coupled fatigue testing instrument.

\section{Experimental Method}

The thermo-mechanical fatigue tests are carried out by utilizing a horizontal-type instrument we developed ourselves [24]. The instrument integrates static-dynamic coupled fatigue testing function with maximum temperature of $1200^{\circ} \mathrm{C}$. As shown in Fig. 1, the tensile and cyclic loads are provided by servomotor and piezoelectric actuator, respectively. $\mathrm{Zr}_{55} \mathrm{Cu}_{30} \mathrm{Al}_{10} \mathrm{Ni}_{5}$ (alloy compositions represent nominal atomic percentages) with amorphous structure is utilized to carry out the fatigue tests at elevated temperatures. A vacuum self-consuming arc melting furnace was used to produce a master alloy ingot; then, the Zr-based bulk amorphous rod with length of $60 \mathrm{~mm}$ and diameter of $8 \mathrm{~mm}$ was prepared by copper mold casting [23]. Regarding the specific size of the specimen, slow-feeding wire cutting process was used to prepare the BMG specimen with notches and doublewedged gripping part; the wedged design would ensure the alignment during the tensile fatigue tests. The length-width ratio of the plate-type BMG specimen is $4: 1$. Also, double-V notched defects are prepared on the specimen's gauge part in order to establish a significant stress concentration coefficient and reduce the corresponding fatigue life. Meanwhile, the high-temperature fatigue crack might be initiated from the tips of V-type notches, which would facilitate the subsequent characterization and analysis of fatigue morphologies. During the thermo-mechanical coupled tests, the applied temperatures are below $T_{g}$, a static tensile stress with magnitude of $90 \%$ tensile strength $\sigma_{b}$ is preloaded, and cyclic load with amplitude of $10 \mathrm{~N}$ and frequency of $50 \mathrm{~Hz}$ is applied until the fatigue fracture occurs ultimately. By using a differential scanning calorimetry (DSC), with a heating rate of $15{ }^{\circ} \mathrm{C} / \mathrm{min}$, the glass transition temperature $T_{g}$ of $412{ }^{\circ} \mathrm{C}$ and the initial crystallization temperature $T_{x}$ of $483{ }^{\circ} \mathrm{C}$ are confirmed, respectively. In order to investigate the effects of temperature on the crystallization behaviors, the applied service temperatures range from room temperature (RT) to $400{ }^{\circ} \mathrm{C}$ (below $T_{g}$ and $T_{x}$ ) with $100{ }^{\circ} \mathrm{C}$ steps.

\section{Results and Discussions}

Figure 2 shows the XRD (X-ray diffraction) pattern of the fatigue fracture surfaces of $\mathrm{Zr}_{55} \mathrm{Cu}_{30} \mathrm{Al}_{10} \mathrm{Ni}_{5} \mathrm{BMG}$ specimens at temperatures ranging from RT to $400{ }^{\circ} \mathrm{C}$. The diffraction patterns of multi-phased mixed crystals are superposed by independent diffraction pattern. The Bragg angle and peak intensity of diffraction pattern of a certain phase are not affected by other phases. Therefore, the XRD pattern analysis used for phase identification, through accurate comparison between PDF (Powder Diffraction File) data and experimental data, could reveal the correlations between the service temperatures, cyclic loads and the crystallization behaviors of $\mathrm{Zr}_{55} \mathrm{Cu}_{30} \mathrm{Al}_{10} \mathrm{Ni}_{5}$ BMG. Specifically, at $\mathrm{RT}$, without cyclic load, $\mathrm{Zr}_{55} \mathrm{Cu}_{30} \mathrm{Al}_{10} \mathrm{Ni}_{5}$ BMG

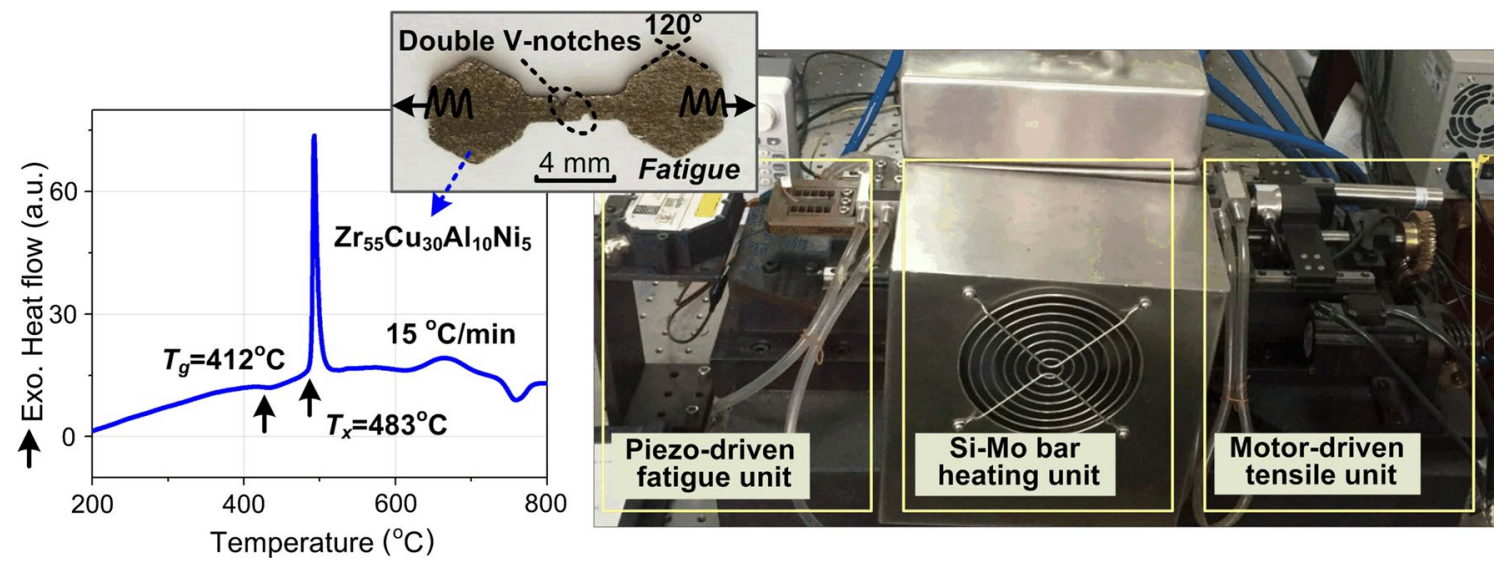

Fig. 1 Thermo-mechanical fatigue testing system integrated with a double- $\mathrm{V}$ notched $\mathrm{Zr}_{55} \mathrm{Cu}_{30} \mathrm{Al}_{10} \mathrm{Ni}_{5} \mathrm{BMG}$ specimen and corresponding DSC curve 


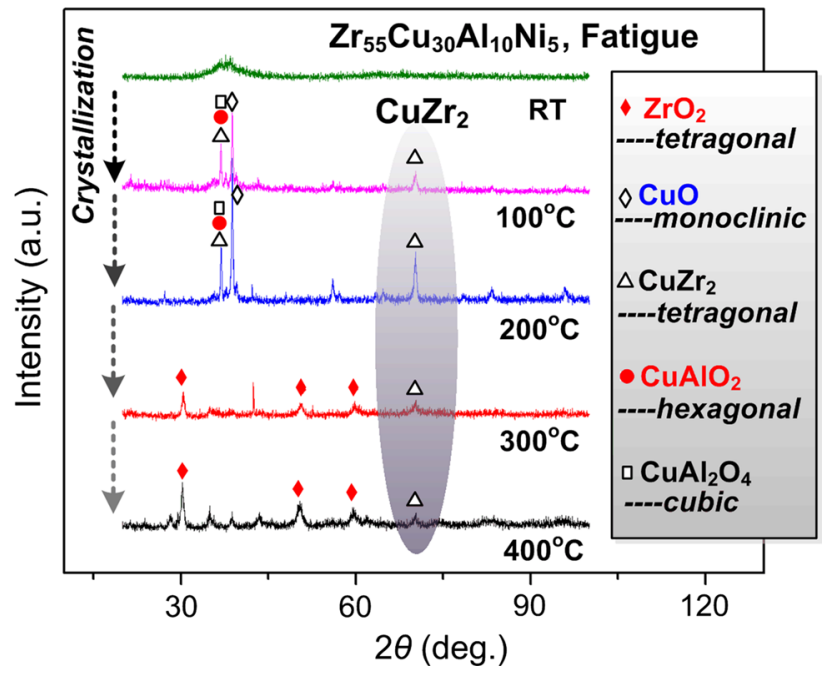

Fig. 2 XRD pattern analysis of $\mathrm{Zr}_{55} \mathrm{Cu}_{30} \mathrm{Al}_{10} \mathrm{Ni}_{5}$ BMG specimens' fatigue surfaces

is definitely amorphous and shows diffusion peaks without obvious diffraction peaks, which accords with the X-ray diffraction data obtained by Louzguine-Luzgin et al. [25]. Although the specimen is subjected to cyclic load with load amplitude of $10 \mathrm{~N}$ and corresponding strain amplitude of $1.2 \times 10^{-3}$ until ultimate fracture, obvious diffusion peak (at diffraction angle with the range from $30^{\circ}$ to $40^{\circ}$ ) rather than visible crystal diffraction peak is observed, which indicates that $\mathrm{Zr}_{55} \mathrm{Cu}_{30} \mathrm{Al}_{10} \mathrm{Ni}_{5}$ BMG does not crystallize at RT regardless of the cyclic load. Similar phenomenon has been verified; as compared with the XRD pattern without cyclic load, after elastic cyclic load, just a slight increase in peak intensity was observed [25]. When the service temperature increases to $100{ }^{\circ} \mathrm{C}$, obvious crystal diffraction peaks appear; besides mixed oxides including monoclinic $\mathrm{CuO}$, hexagonal $\mathrm{CuAlO}_{2}$ and cubic $\mathrm{CuAl}_{2} \mathrm{O}_{4}$, non-oxidized phase $\mathrm{CuZr}_{2}$ is also observed on the specimen's fracture surface. The oxide composition is in general accord with the report of Sun et al. [16]. This phenomenon indicates the non-oxidized crystallization process is motivated and promoted by applying cyclic load. Especially for the generation and precipitation of binary alloy $\mathrm{CuZr}_{2}$ at a temperature by far lower than $T_{g}$, which has not been reported in the previous literatures, however, Kai et al. [26] noted that $\mathrm{Zr}_{2} \mathrm{Cu}$ phase was detected and indicated that the amorphous alloy begins to crystallize after oxidation at $425{ }^{\circ} \mathrm{C}$. Regarding the fracture obtained from $200{ }^{\circ} \mathrm{C}$ fatigue test, the XRD pattern shows similar crystal diffraction peaks on the basis of the same diffraction angles, and the mixed oxides and non-oxidized phase $\mathrm{CuZr}_{2}$ are also observed. However, compared with the peaks obtained from $100{ }^{\circ} \mathrm{C}$ fatigue XRD pattern, the intensity and area of diffraction peaks gradually increase. Therefore, the grain growth with the increment of temperature is indirectly confirmed. When the temperature increases to $300{ }^{\circ} \mathrm{C}$, the preexisting mixed oxides are entirely covered by the newly generated tetragonal crystalline $\mathrm{ZrO}_{2}$. Nie et al. [27] also revealed the similar covering procedure of oxide, and a $\mathrm{ZrO}_{2}$-enriched oxide layer with film thickness of 150-260 nm was detected. Meanwhile, tetragonal crystalline $\mathrm{CuZr}_{2}$ phase exists simultaneously. In addition, seen from the $400{ }^{\circ} \mathrm{C}$ fatigue XRD patterns, as the temperature already approaches $T_{g}$, the oxidation process further aggravates, but considering the diffraction peaks with increased intensity and area actually correspond to $\mathrm{ZrO}_{2}$ rather than $\mathrm{CuZr}_{2}$, non-oxidized $\mathrm{CuZr}_{2}$ might be gradually covered by the growing $\mathrm{ZrO}_{2}$. The above phenomenon reveals the novel crystallization behaviors of $\mathrm{Zr}_{55} \mathrm{Cu}_{30} \mathrm{Al}_{10} \mathrm{Ni}_{5}$ BMG. Under thermo-mechanical coupled fatigue loading conditions, obvious non-oxidized crystallization is confirmed on the basis of relatively lower temperatures below $T_{g}$.

In order to verify the covering process of $\mathrm{Zr}$-based $\mathrm{BMG}$ by high-temperature-induced oxide $\mathrm{ZrO}_{2}$, the fatigue fracture morphologies [28] of $\mathrm{Zr}_{55} \mathrm{Cu}_{30} \mathrm{Al}_{10} \mathrm{Ni}_{5}$ BMGs under various temperatures are obtained by scanning electron microscope (SEM). Seen from the morphology obtained from RT fatigue test (Fig. 3a), similar to the study of Lee et al. [19], the morphology examination reveals a dimplelike morphology interspersed with several groups of layered patterns. Regarding the $200{ }^{\circ} \mathrm{C}$ fatigue morphology as shown in Fig. 3b, layered floccules with height difference in micrometer level show the roughness evolution of fracture surface due to the effect of temperature rise, as the previous non-oxidizing dimples are gradually covered by mixed oxides. At $300{ }^{\circ} \mathrm{C}$ (Fig. 3c), aggravated floccules promote the irregular roughness of surface morphologies, which suggests the continuous growth process of mixed oxides. Although the XRD patterns show that the BMG's fatigue surface is entirely covered by newly generated $\mathrm{ZrO}_{2}$ and $\mathrm{CuZr}_{2}$, the SEM image merely shows an initial nucleation of $\mathrm{ZrO}_{2}$ until a large amount of growing and crystallized $\mathrm{ZrO}_{2}$ is observed [29] as shown in Fig. 3d. Moreover, at $400{ }^{\circ} \mathrm{C}$, combined with the diffraction peaks with increased intensity and area of $\mathrm{ZrO}_{2}$, homogeneous spheroidal particles of $\mathrm{ZrO}_{2}$, which is characterized through energy spectrum analysis, are observed to attach to the specimen's fracture surface and would further aggravate the roughness of the surface. The newly grown $\mathrm{ZrO}_{2}$ nanofibers, originating from the surface of the particles, are also observed. Regarding the material composition of precipitated homogeneous particles, according to the statements of Kai et al. [26] and Sharma et al. [29], $\mathrm{ZrO}_{2}$ was also detected through phase identification.

To further explain the thermo-mechanical coupled effects on the crystallization behaviors of $\mathrm{Zr}_{55} \mathrm{Cu}_{30} \mathrm{Al}_{10} \mathrm{Ni}_{5} \mathrm{BMG}$, on the basis of constant temperature of $400{ }^{\circ} \mathrm{C}$, XRD patterns, respectively, obtained from static tensile fracture and creep fracture are compared with the pattern obtained from 

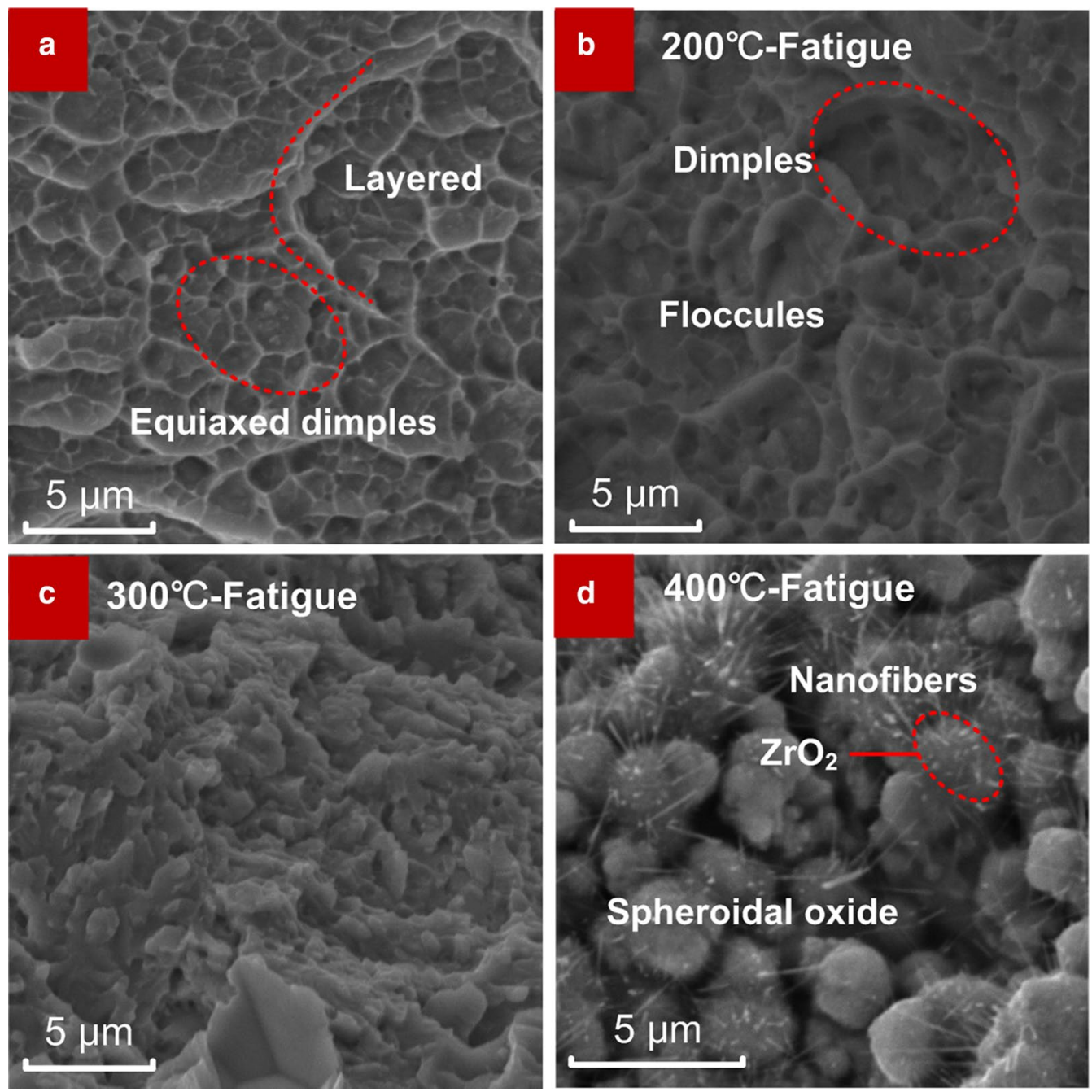

Fig. 3 Fatigue fracture morphologies, respectively, obtained from a RT fatigue test, $\mathbf{b}-\mathbf{d}$ thermo-mechanical coupled fatigue tests as an increase in temperature ranging from 200 to $400{ }^{\circ} \mathrm{C}$

fatigue fracture. As shown in Fig. 4, regarding the $400{ }^{\circ} \mathrm{C}$ tensile XRD pattern, on the basis of a constant tensile speed of $2 \mathrm{um} / \mathrm{s}$, mixed oxides only containing $\mathrm{CuO}$ and $\mathrm{ZrO}_{2}$ are observed. Regarding the creep fracture with creep time over $31.5 \mathrm{~h}, \mathrm{ZrO}_{2}$ is the only produced crystalline substance. Kai et al. [26] described the oxidation kinetics and precipitation of $\mathrm{Zr}_{2} \mathrm{Cu}$ in detail. They indicated that the oxidation kinetics of $\mathrm{Zr}_{55} \mathrm{Cu}_{30} \mathrm{Al}_{10} \mathrm{Ni}_{5}$ BMG consists of initial, transient and steady-state stages. During the creep test at temperature $\geq 350{ }^{\circ} \mathrm{C}, \mathrm{ZrO}_{2}$ is the major product formed on the oxidized surface, and $\mathrm{Zr}_{2} \mathrm{Cu}$ phase is merely detected at temperature $\geq 425^{\circ} \mathrm{C}$, which indicates that the BMG begins to crystallize after oxidation at $425{ }^{\circ} \mathrm{C}$ without cyclic load. The longtime heating and holding procedures have promoted the growth of $\mathrm{ZrO}_{2}$, which accords with the analysis obtained from XRD pattern and SEM images. Therefore, without cyclic loading conditions, only oxides rather than non-oxidized phases appear on the BMG specimen's surface,

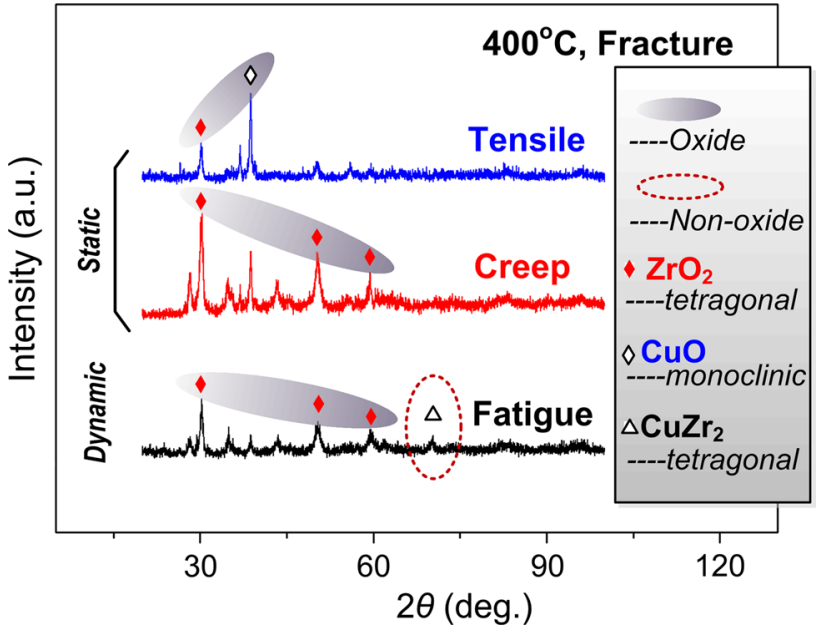

Fig. 4 XRD pattern analysis of $\mathrm{Zr}_{55} \mathrm{Cu}_{30} \mathrm{Al}_{10} \mathrm{Ni}_{5}$ BMG specimens' fracture surfaces, respectively, obtained from static tensile, creep and fatigue fractures 

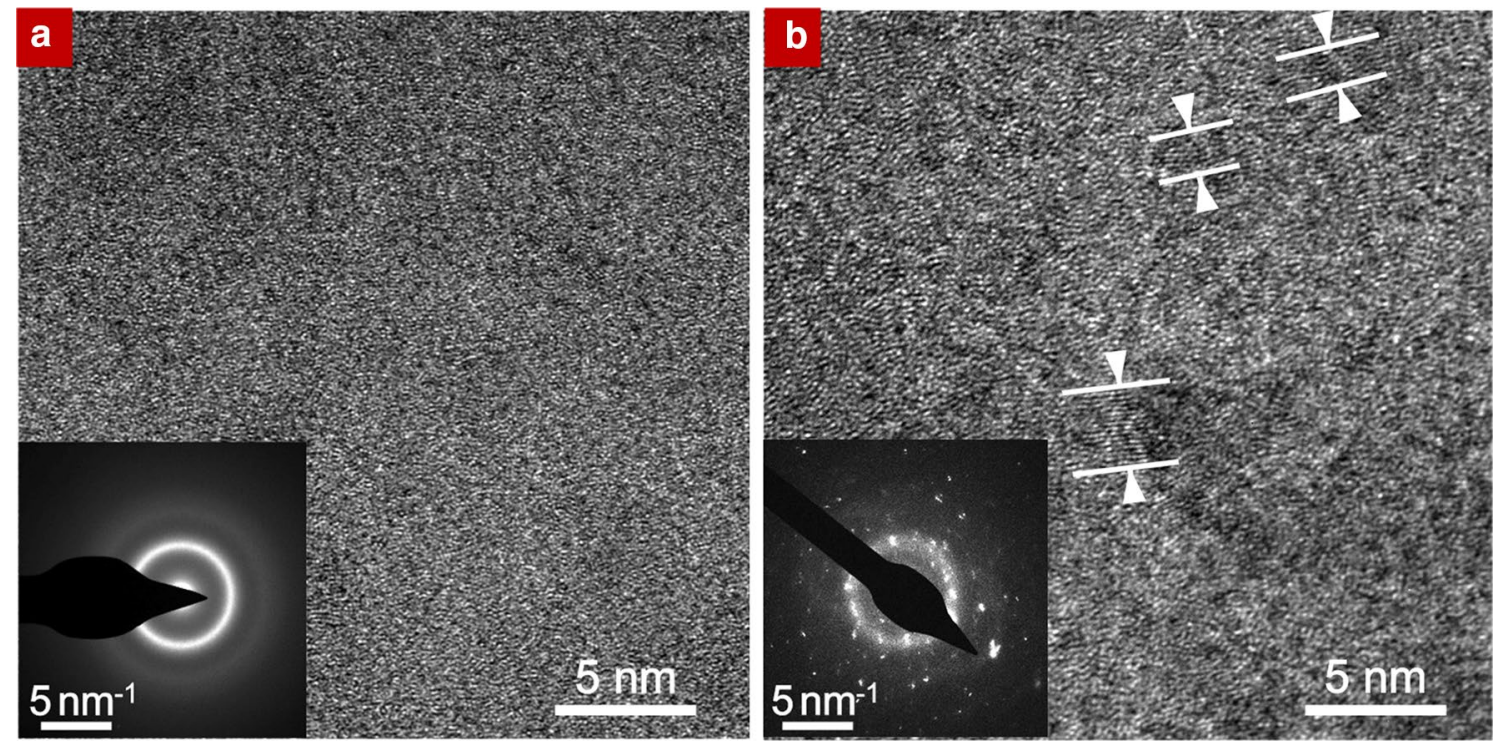

Fig. 5 TEM micrographs and diffraction patterns of $\mathrm{Zr}_{55} \mathrm{Cu}_{30} \mathrm{Al}_{10} \mathrm{Ni}_{5}$ specimens after a RT fatigue, $\mathbf{b} 100{ }^{\circ} \mathrm{C}$ fatigue tests to illustrate the crystallization of amorphous phases

which further indicates that the cyclic load acts as an important role on the generation of non-oxidized crystal phases of $\mathrm{Zr}_{55} \mathrm{Cu}_{30} \mathrm{Al}_{10} \mathrm{Ni}_{5}$ BMG at temperature by far below $T_{g}$. The effect of cyclic load on the crystallization behavior is in general accord with the report of Kato et al. [23], as the crystallization in weakly bonded regions of BMG at a low temperature under the ultrasonic vibrations is explained by the accumulation of atomic jumps.

Furthermore, transmission electron microscope (TEM) investigations are performed to reveal the microstructural features and diffraction pattern. Figure $5 \mathrm{a}, \mathrm{b}$ shows the bright-field micrographs of fractured Zr-based BMG specimens subjected to cyclic load at RT and constant temperature of $100{ }^{\circ} \mathrm{C}$, respectively. Similar to the XRD pattern analysis in Fig. 2, the cyclic loading process at RT does not induce obvious crystallization, as the TEM micrograph shows mazelike patterns that confirm the glassy nature of amorphous phase [7], and a typical halo ring without spot distribution is observed in the selected area electron diffraction (SAED) pattern. Meanwhile, it can be clearly recognized that the BMG subjected to thermo-mechanical coupled fatigue loading condition is composed of isolated dark zones (nanocrystals) with size ranging from 2 to $5 \mathrm{~nm}$, and the nanocrystals with regular lattice fringes are surrounded by amorphous domains with continuous bright zones. The volume fraction of the dark zones is estimated as approximate $5.8 \%$. The SAED patterns in typical dark zone include a crystallized phase and amorphous matrix, as obvious spot distributions around a halo ring in the SAED patterns are observed [21]. Therefore, compared with the cyclic load, the effect of temperature is more critical. However, combined with the static tensile and creep testing results, the cyclic load is also indispensable to induce crystallization. The coupling effects of cyclic load and low temperature $\left(100^{\circ} \mathrm{C}\right)$ on the crystallization of amorphous phases are verified.

\section{Conclusion}

At temperatures by far lower than $T_{g}, \mathrm{Zr}_{55} \mathrm{Cu}_{30} \mathrm{Al}_{10} \mathrm{Ni}_{5}$ BMG exhibits novel oxidation and crystallization behaviors. Based on various temperatures ranging from $\mathrm{RT}$ to $400{ }^{\circ} \mathrm{C}$, the relevance between generation sequences of oxides and cyclic load is described in detail. The initial oxides $\left(\mathrm{CuO}, \mathrm{CuAlO}_{2}\right.$, $\mathrm{CuAl}_{2} \mathrm{O}_{4}$ ) generated below $200{ }^{\circ} \mathrm{C}$ are gradually covered by high-temperature-generated oxide $\mathrm{ZrO}_{2}$ over $300{ }^{\circ} \mathrm{C}$. The effects of temperature and cyclic load are indispensable conditions to produce non-oxidized phase $\mathrm{CuZr}_{2}$. Particularly, the initial temperature $\left(100{ }^{\circ} \mathrm{C}\right)$ determining the precipitation of binary alloy $\mathrm{CuZr}_{2}$ is by far lower than $T_{g}$. Without cyclic load, even though relatively higher temperature $\left(400{ }^{\circ} \mathrm{C}\right.$ ), quasi-static tensile load and creep load (lasting for $31.5 \mathrm{~h}$ ) are applied, non-oxidized nanocrystals are not observed from XRD patterns. TEM micrographs and diffraction patterns obtained from RT fatigue and $100{ }^{\circ} \mathrm{C}$ fatigue fractures also indicate the dominating effect of cyclic load on the generation of non-oxidized, as obvious spot distributions and nanocrystals are directly observed.

Acknowledgements This work is funded by the National Natural Science Foundation of China (51875241, 51505180, U1601203), the Jilin Province Science and Technology Development Plan 
(20180201126GX, 20170101134JC) and the China Postdoctoral Science Foundation Funded Project (2017T100205).

\section{References}

[1] Q.S. Zeng, H.W. Sheng, Y. Ding, L. Wang, W.G. Yang, Z.J. Jiang, W.L. Mao, H.K. Mao, Science 320, 1404 (2011)

[2] W.H. Sheng, W.K. Luo, F.M. Alamgir, J.M. Bai, E. Ma, Nature 439, 419 (2006)

[3] Y.H. Sun, A. Concustell, A.L. Greer, Nat. Rev. Mater. 16039, 1 (2016)

[4] Z.P. Lu, C.T. Liu, Acta Mater. 50, 3501 (2002)

[5] Y.Y. Xi, J. He, X.J. Sun, W. Li, J.Z. Zhao, H.R. Hao, T. Xiong, Acta Metall. Sin. (Engl. Lett.) 31, 1130 (2018)

[6] H.J. Yang, J.W. Qiao, S. Wang, Y. Zhang, Acta Metall. Sin. (Engl. Lett.) 27, 621 (2014)

[7] Y.H. Liu, G. Wang, R.J. Wang, D.Q. Zhao, M.X. Pan, W.H. Wang, Science 315, 1385 (2007)

[8] W.L. Johnson, G. Kaltenboeck, M.D. Demetriou, J.P. Schramm, X. Liu, K. Samwer, C.P. Kim, D.C. Hofmann, Science 332, 828 (2011)

[9] L.M. Zhou, S.H. Ren, C.Y. Liu, Z.C. Ma, Compos. Struct. 208, 298 (2019)

[10] C.C. Wang, Y.W. Mao, Z.W. Shan, M. Dao, J. Li, J. Sun, E. Ma, Proc. Natl. Acad. Sci. 10, 19725 (2013)

[11] Z.J. Yan, K.K. Song, Y. Hu, F.P. Dai, Z.B. Chu, J. Eckert, Sci. Rep-UK 6, 19358 (2016)

[12] G.C. Ma, Z.W. Zhu, Z. Wang, H.F. Zhang, J. Mater. Sci. Technol. 31, 941 (2015)

[13] J.A. Clinton, R.L. Morrison, J.L.W. Carter, Metall. Mater. Trans. A 48, 3220 (2017)
[14] S.V. Ketov, Y.H. Sun, S. Nachum, Z. Lu, A. Checchi, A.R. Beraldin, H.Y. Bai, W.H. Wang, D.V. Louzguine-Luzgin, M.A. Carpenter, A.L. Greer, Nature 524, 200 (2015)

[15] D.Y. Wu, K.K. Song, P. Gargarella, C.D. Cao, R. Li, I. Kaban, J. Eckert, J. Alloys Compd. 664, 99 (2016)

[16] X. Sun, S. Schneider, U. Geyer, W.L. Johnson, M.A. Nicolet, J. Mater. Res. 11, 2378 (1996)

[17] Y.W. Mao, J. Li, Y.C. Lo, X.F. Qian, E. Ma, Phys. Rev. B 91, 214013 (2015)

[18] J.J. Lewandowski, A.L. Greer, Nat. Mater. 5, 15 (2006)

[19] D.G. Lee, Y.G. Kim, B. Hwang, S. Lee, Y.T. Lee, Mater. Sci. Eng., A 472, 316 (2008)

[20] R.E. Pawel, J. Electrochem. Soc. 109, 1111 (1979)

[21] J.J. Kim, Y. Choi, S. Suresh, A.S. Argon, Science 295, 654 (2002)

[22] W. Kai, I.F. Ren, P.C. Kao, R.F. Wang, X.P. Chuang, M.W. Freels, P.K. Liaw, Adv. Eng. Mater. 11, 380 (2009)

[23] H. Kato, T. Ichitsubo, H. Igarashi, A. Inoue, Appl. Phys. Lett. 95, $231911(2009)$

[24] Z.C. Ma, X.J. Du, H.W. Zhao, X.X. Ma, D.Y. Jiang, Y. Liu, L.Q. Ren, Rev. Sci. Instrum. 89, 016102 (2018)

[25] D.V. Louzguine-Luzgin, V.Y. Zadorozhnyy, S.V. Ketov, Z. Wang, A.A. Tsarkov, A.L. Greer, Acta Mater. 129, 343 (2017)

[26] W. Kai, H.H. Hsieh, T.G. Nieh, Y. Kawamura, Intermetallics 10, $1265(2002)$

[27] X.P. Nie, X.H. Yang, Y. Ma, L.Y. Chen, K.B. Yeap, K.Y. Zeng, D. Li, J.S. Pan, X.S. Wang, Q.P. Cao, S.Q. Ding, J.Z. Jiang, Intermetallics 22, 74 (2012)

[28] G.Y. Gao, P.K. Liaw, O.N. Senkov, D.B. Miracle, Adv. Eng. Mater. 11, 27 (2009)

[29] S.K. Sharma, T. Strunskus, H. Ladebusch, F. Faupel, Mater. Sci. Eng., A 304, 747 (2001) 